\title{
Localized hypermutation and associated gene losses in legume chloroplast genomes
}

\author{
Alan M. Magee, ${ }^{1}$ Sue Aspinall, ${ }^{2}$ Danny W. Rice, ${ }^{3}$ Brian P. Cusack, ${ }^{1}$ Marie Sémon, ${ }^{4}$ \\ Antoinette S. Perry, ${ }^{1}$ Saša Stefanović, ${ }^{5}$ Dan Milbourne, ${ }^{6}$ Susanne Barth, ${ }^{6}$ \\ Jeffrey D. Palmer, ${ }^{3}$ John C. Gray, ${ }^{2}$ Tony A. Kavanagh, ${ }^{1}$ and Kenneth H. Wolfe ${ }^{1,7}$ \\ ${ }^{1}$ Smurfit Institute of Genetics, Trinity College, Dublin 2, Ireland; ${ }^{2}$ Department of Plant Sciences, University of Cambridge, Cambridge \\ CB2 3EA, United Kingdom; ${ }^{3}$ Department of Biology, Indiana University, Bloomington, Indiana 47405, USA; ${ }^{4}$ Institut de Génomique \\ Fonctionnelle de Lyon, Université de Lyon, CNRS, INRA, UCB Lyon 1, Ecole Normale Supérieure de Lyon, 69364 Lyon Cedex 07 , France; \\ ${ }^{5}$ Department of Biology, University of Toronto, Mississauga, Ontario L5L 1C6, Canada; ${ }^{6}$ Teagasc Crops Research Centre, Oak Park, \\ Carlow, Ireland
}

\begin{abstract}
Point mutations result from errors made during DNA replication or repair, so they are usually expected to be homogeneous across all regions of a genome. However, we have found a region of chloroplast DNA in plants related to sweetpea (Lathyrus) whose local point mutation rate is at least 20 times higher than elsewhere in the same molecule. There are very few precedents for such heterogeneity in any genome, and we suspect that the hypermutable region may be subject to an unusual process such as repeated DNA breakage and repair. The region is $1.5 \mathrm{~kb}$ long and coincides with a gene, ycf4, whose rate of evolution has increased dramatically. The product of $y c f 4$, a photosystem I assembly protein, is more divergent within the single genus Lathyrus than between cyanobacteria and other angiosperms. Moreover, ycf4 has been lost from the chloroplast genome in Lathyrus odoratus and separately in three other groups of legumes. Each of the four consecutive genes ycf4-psal-accD-rps16 has been lost in at least one member of the legume "inverted repeat loss" clade, despite the rarity of chloroplast gene losses in angiosperms. We established that $\operatorname{acc} D$ has relocated to the nucleus in Trifolium species, but were unable to find nuclear copies of ycf4 or psal in Lathyrus. Our results suggest that, as well as accelerating sequence evolution, localized hypermutation has contributed to the phenomenon of gene loss or relocation to the nucleus.
\end{abstract}

[Supplemental material is available online at http://www.genome.org. The sequence data from this study have been submitted to GenBank (http:// www.ncbi.nlm.nih.gov/Genbank/) under accession nos. HM029359-HM029371, HM048906HM048910, and GO313838-GO322539.]

The genome organization and gene content of chloroplast DNA (cpDNA) are highly conserved among most flowering plant species (Palmer 1985; Sugiura 1992; Jansen et al. 2007). The chloroplast genome of the most recent common ancestor of all angiosperms contained 113 different genes (four rRNA genes, 30 tRNA genes, and 79 protein genes), and this content has been retained in many angiosperms (Kim and Lee 2004). Rates of synonymous nucleotide substitution in chloroplast genes are generally low (a few fold lower than plant nuclear genes) and relatively homogeneous within a genome except for a threefold difference in rate between the large inverted repeat (IR) and single-copy regions (Wolfe et al. 1987; Drouin et al. 2008). Lineage-specific variation in chloroplast synonymous rates has been documented (Gaut et al. 1993; Guo et al. 2007) but is relatively modest compared to the vast differences seen among some plant mitochondrial lineages (Palmer et al. 2000; Mower et al. 2007; Sloan et al. 2009).

Some angiosperm cpDNAs have fewer than the 79 canonical protein genes due to gene losses. Most notable here are parasitic plants such as Cuscuta and Epifagus that have lost some or all photosynthetic ability (Wolfe et al. 1992; Funk et al. 2007; McNeal et al. 2007). Chloroplast gene losses are rarer in photosynthetic species, because in many cases the gene cannot simply be discarded and must instead be either functionally transferred to the

\footnotetext{
${ }^{7}$ Corresponding author.

E-mail khwolfe@tcd.ie.

Article published online before print. Article and publication date are at http://www.genome.org/cgi/doi/10.1101/gr.111955.110.
}

nuclear genome or functionally replaced by a nuclear gene ("gene substitution"). Successful gene transfers from the chloroplast to the nuclear genome during angiosperm evolution have been reported for $r p l 22$ in legumes (Gantt et al. 1991); for infA in several lineages, including almost all rosids (Millen et al. 2001); and for rpl32 in two families of Malpighiales (Cusack and Wolfe 2007; Ueda et al. 2007). In addition, Ueda et al. (2008) identified gene substitution as the mechanism of loss of the rps16 gene from cpDNA in Medicago and Populus. The loss of rps16 from cpDNA is compensated by dual targeting (to chloroplasts as well as mitochondria) of mitochondrial ribosomal protein $\mathrm{S} 16$, which is encoded by a nuclear gene. Several other examples of losses of genes from cpDNA in photosynthetic angiosperms have been reported, and it is striking that the few species in which gene losses have occurred tend also to be those whose chloroplast genomes are highly rearranged relative to the ancestral angiosperm organization (Jansen et al. 2007). As with angiosperm mitochondrial genomes (Adams and Palmer 2003), most of the genes that have been lost from chloroplast genomes during recent evolution have coded for ribosomal proteins (Jansen et al. 2007). There have been no published reports of the loss of genes coding for components of photosystems I or II ( $p s a$ and $p s b$ genes), the electron transfer chain (pet genes), or the chloroplast ATP synthase (atp genes) from cpDNA in any angiosperms except parasitic species (Wolfe et al. 1992; Funk et al. 2007; McNeal et al. 2007).

One group of angiosperms that is known to be relatively prone to cpDNA rearrangement and gene loss is the legume family 
(Fabaceae) (Palmer et al. 1988). The large IR that is otherwise almost universally present in chloroplast genomes is absent from one large clade of legumes (the IR loss clade, or IRLC) (Wojciechowski et al. 2004), some of which also show other rearrangements of gene order. Chloroplast genomes in the IRLC species are also notable for having significant amounts of repetitive DNA, something not usually seen in angiosperm cpDNA (Milligan et al. 1989; Saski et al. 2005; Cai et al. 2008). Five instances of gene loss from the IRLC chloroplast genomes have been discovered. As well as the aforementioned gene transfers of $r p l 22$ and infA and substitution of rps16 (Gantt et al. 1991; Millen et al. 2001; Ueda et al. 2008), it has been reported that that $a c c D$ is completely absent from Trifolium subterraneum (subclover) cpDNA, and that ycf4 in Pisum sativum (pea) is either absent or a pseudogene (Nagano et al. 1991a; Smith et al. 1991; Cai et al. 2008). Slot-blot hybridization experiments suggested that $y c f 4$ and rps16 may have been lost independently multiple times in different lineages of legumes (Doyle et al. 1995).

In the course of this study, we reviewed all reported instances (in published papers or in GenBank annotations) of gene loss among the 103 complete angiosperm chloroplast genome sequences that are publicly available, and found that 27 different protein-coding genes have been lost in at least one lineage (Supplemental Table S1). We found that some reported gene losses are simply due to annotation errors; because of this, the numbers of losses we describe here are slightly different from those in Jansen et al. (2007). In particular, we noticed that the gene $y c f 4$, which was originally not identified in the genome sequences of the legumes Glycine max (soybean; Saski et al. 2005), T. subterraneum (subclover; Cai et al. 2008), Cicer arietinum (chickpea), and Medicago truncatula (Jansen et al. 2008), is in fact present in the cpDNAs of all these species but is so divergent that it was not recognized by the DOGMA software (Wyman et al. 2004) used to annotate them. This discovery prompted us to investigate the rapid evolution of $y c f 4$ and its surrounding region in legumes.

Ycf4 is a thylakoid protein that has been shown to play a role in regulating photosystem I assembly in cyanobacteria (Wilde et al. 1995) and to be essential for photosystem I assembly in Chlamydomonas (Boudreau et al. 1997; Onishi and Takahashi 2009). Experiments in Chlamydomonas indicate that Ycf4 is the second of three scaffold proteins that act sequentially during the assembly process, with Ycf4's roles being to stabilize an intermediate subcomplex consisting of the PsaAB heterodimer and the three stromal subunits PsaCDE, and to add the PsaF subunit to this subcomplex (Ozawa et al. 2009). As well as the loss of $y c f 4$ in P. sativum, several other previous studies have indicated that the evolution of $y c f 4$ in legumes may be unusual. In soybean and Lotus japonicus, the Ycf4 protein, which is almost universally 184 or 185 amino acids long, has expanded to about 200 residues (Reverdatto et al. 1995; Kato et al. 2000). The gene also has a high rate of synonymous nucleotide substitution between the latter two species (Perry and Wolfe 2002). Phylogenetic trees for phaseoloid legumes constructed using $y c f 4$ were incongruent with trees constructed using seven other genes, due to accelerated evolution of codon positions 1 and 2 in $y c f 4$ (Stefanovic et al. 2009). In blot hybridizations to DNAs from 280 diverse angiosperms (as in Millen et al. 2001) using a $y c f 4$ probe from tobacco, we observed (SS and JDP, unpubl.) strong hybridization to all DNAs except those from the only Papillionoid legumes surveyed: Medicago (no signal from five species) and Vigna (considerably diminished signal). We show here that $y c f 4$ is situated in a local mutation hotspot, in Lathyrus, and possibly in other legume species, resulting in dramatic acceleration of sequence evolution in some species and evolutionary gene losses in others.

\section{Results}

\section{Rapid evolution of $y c f 4$ in legumes}

To investigate acceleration of the evolutionary rate of $y c f 4$ in legumes, we compared its nonsynonymous and synonymous nucleotide substitution rates in different angiosperm lineages to the rates observed in two other, widely sequenced chloroplast genes, $r b c L$ and $m a t K$. This analysis included new $y c f 4$ sequence data from Lathyrus and other legumes, together with sequences from a previous phylogenetic study (GenBank [http://www.ncbi.nlm.nih. gov/Genbank/] accession nos. EU717431-EU717464; Stefanovic et al. 2009) and other database sequences. For each gene, we used a likelihood model to estimate the numbers of nonsynonymous $\left(d_{\mathrm{N}}\right)$ and synonymous $\left(d_{\mathrm{S}}\right)$ nucleotide substitutions that occurred on each branch of an angiosperm phylogenetic tree (see Methods). In the $d_{\mathrm{N}}$ trees, $y c f 4$ is seen to evolve much faster in most legumes than in other angiosperms (Fig. 1) but no similar acceleration is seen in legume $r b c L$ or $m a t K$, which suggests that the acceleration is locus-specific, as well as lineage-specific. Within legumes, the first accelerated branch is the one leading to a large clade (Millettioids, Robinioids, and the IRLC; asterisk in Fig. 1), and the legumes that are outgroups to this branch do not show acceleration. This branch is also the first one on which the Ycf4 protein size expands above 200 amino acids (Fig. 1). Even faster periods of $d_{\mathrm{N}}$ evolution are seen in the genera Desmodium and Lathyrus relative to other legumes. Ycf4 is a pseudogene in three of six Desmodium species we sequenced and in Clitoria ternatea (Supplemental Fig. S1C, left panel). In the $d_{\mathrm{S}}$ trees, some acceleration is seen in $y c f 4$ of legumes relative to other angiosperms, particularly in Lathyrus, but again no similar acceleration is seen in legume $r b c L$ or matK (Fig. 1). The genus Lathyrus also shows by far the greatest increases in Ycf4 size, reaching 340 residues in Lathyrus latifolius and Lathyrus cirrhosus.

Remarkably, there is less amino acid sequence conservation between the Ycf4 proteins of two species within the genus Lathyrus (31\% identity between Lathyrus palustris and L. cirrhosus), than between tobacco and the cyanobacterium Synechocystis (45\% identity). Nevertheless, $y c f 4$ can be inferred to be functional in the four Lathyrus species in which it is intact (Fig. 2), for two reasons. First, even though the level of amino acid sequence conservation among Lathyrus species is very low, many of the sites in the C-terminal part of the protein (beginning at position 248 in Fig. 2) that are conserved among other land plants and cyanobacteria are also conserved in Lathyrus. Second, comparing ycf4 sequences among Lathyrus species shows that they have lower levels of nonsynonymous than synonymous nucleotide substitutions $\left(d_{\mathrm{N}} /\right.$ $d_{\mathrm{S}}<1$ ) (Table 1), which is a hallmark of sequences that are being constrained to code for proteins (Kimura 1977; Graur and Li 1999). We therefore infer that these long ycf4 genes in Lathyrus species are biologically functional. However, the level of constraint on Lathyrus ycf4 is lower than on other angiosperm $y c f 4$ s (e.g., $d_{\mathrm{N}} / d_{\mathrm{S}}=$ 0.15 between tobacco and spinach $y c f 4$, compared with $d_{\mathrm{N}} / d_{\mathrm{S}}=$ 0.36-0.81 within the genus Lathyrus). Tests for positive (Darwinian) selection suggested that some Desmodium branches within the $y c f 4$ tree have undergone adaptive evolution, and in separate analyses, site-specific tests for positive selection were significant for some codons in $y c f 4$ when the whole legume tree was considered (data not shown). However, in view of the evidence that the whole region around $y c f 4$ has a high mutation rate (see below), and 

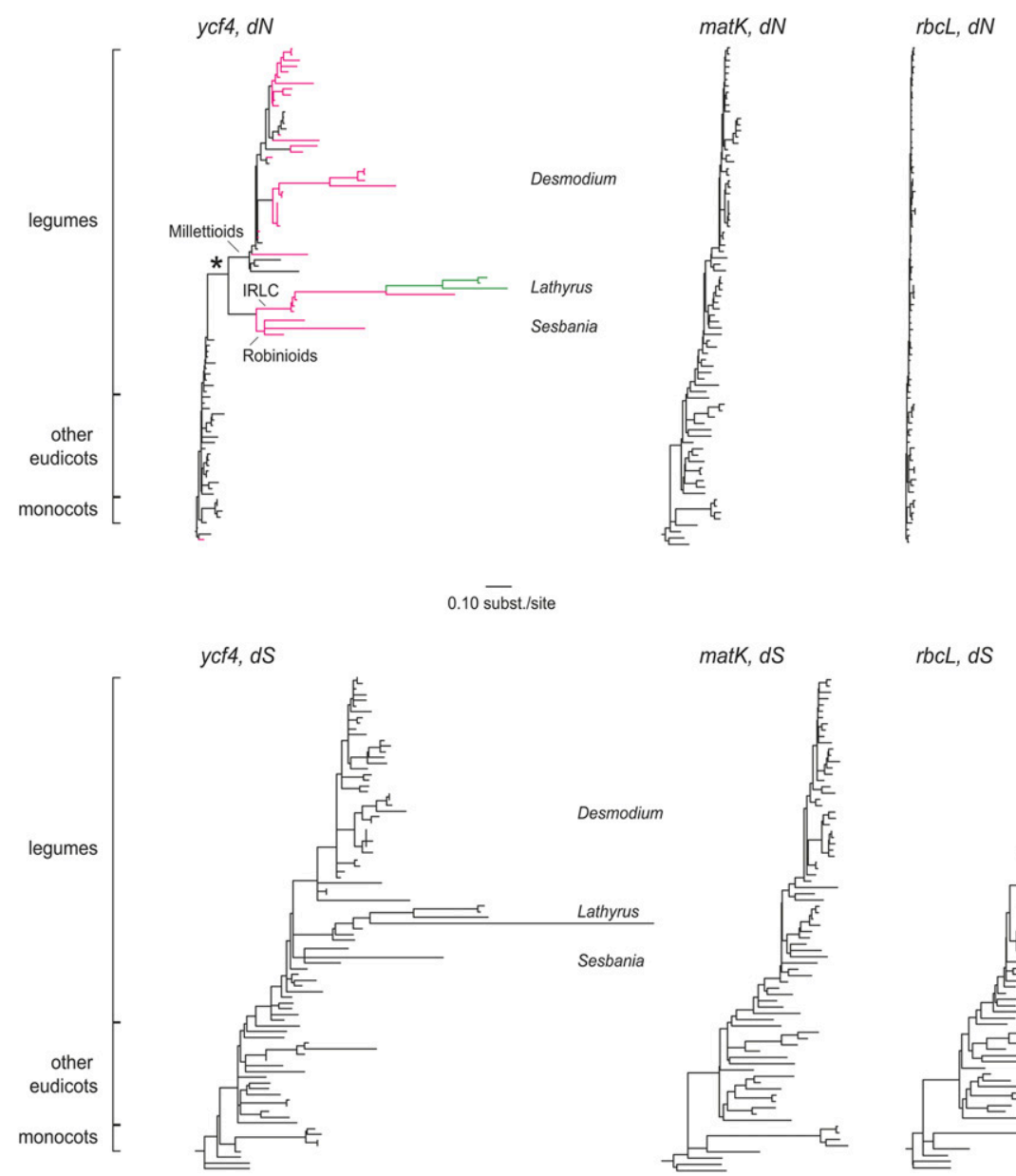

Figure 1. Synonymous and nonsynonymous divergence in angiosperm chloroplast ycf4 sequences. Shown are $d_{\mathrm{N}}$ (upper) and $d_{\mathrm{S}}$ (lower) trees resulting from a codon-based likelihood analysis and a constrained topology, rooted using gymnosperm sequences (which are not included in the trees). All trees are drawn to the same scale. The species are in the same order from top to bottom in all trees, to the greatest extent possible, and are named in full in Supplemental Figure S1. Magenta branches in the $d_{\mathrm{N}}$ tree for $y c f 4$ indicate those on which the Ycf4 protein length is (or is inferred to have been) $\geq 200$ amino acid residues; green branches indicate lengths $\geq 300$ residues. The asterisk marks the branch (leading to Millettioids, Robinioids, and IRLC) in which rate acceleration is first seen. Trees for chloroplast $r b c L$ and matK genes do not show comparable rate heterogeneity at either synonymous or nonsynonymous sites.

because we also found some $d_{\mathrm{N}} / d_{\mathrm{S}}$ values greater than 1 within the genus Lathyrus for two genes flanking ycf4 (cemA and accD) (Table 1 ), we suspect that the high $d_{\mathrm{N}} / d_{\mathrm{S}}$ values are artifacts stemming from a combination of an increased mutation rate and lessened constraints on protein sequences, rather than being indicative of positive selection on multiple adjacent genes.

We may have slightly overestimated the divergence of Lathyrus Ycf4 proteins because we inferred protein sequences from chloroplast DNA sequences, whereas some chloroplast transcripts are known to undergo mRNA editing (Stern et al. 2010). Editing in angiosperms involves $\mathrm{C} \rightarrow \mathrm{U}$ changes and typically occurs at 30-40 sites per genome (Tsudzuki et al. 2001; Inada et al. 2004). However, even extensive $\mathrm{C} \rightarrow \mathrm{U}$ editing could only marginally reduce the divergence in Lathyrus Ycf4. For example, if we assume that every possible $\mathrm{C} \rightarrow \mathrm{U}$ editing event that could increase the similarity between $L$. palustris and L. cirrhosus Ycf4 proteins actually occurs, their sequence identity only increases from $31 \%$ to $32 \%$. Furthermore, no sites in $y c f 4$ are known to undergo mRNA larly repetitive structure, but the sections of the gene that are repeated are different in the two species (Supplemental Fig. S2B,C). There are tandem repeats in the intergenic DNA between accD and $y c f 4$ in L. latifolius (Supplemental Fig. S2D), and a tandem repeat of 15 codons is located within the $5^{\prime}$ end of L. sativus ycf4 (Supplemental Fig. S2B). All the repeats are species-specific, which suggests that these minisatellite-like sequences have a high turnover rate. However, some other species, such as L. odoratus, do not contain tandem repeats in this region, and the expanded size of $y c f 4$ in most Lathyrus species is not primarily due to the accumulation of repeats.

\section{Sequences of the $P$. sativum and $L$. sativus chloroplast genomes}

To establish whether the patterns of evolution seen around the $y c f 4$ locus are atypical of the rest of the genome, we sequenced the chloroplast genome of L. sativus (grasspea; 121,020 bp) and completed the genome sequence of $P$. sativum cpDNA (pea; $122,169 \mathrm{bp}$ )

\section{Genome Research www.genome.org}




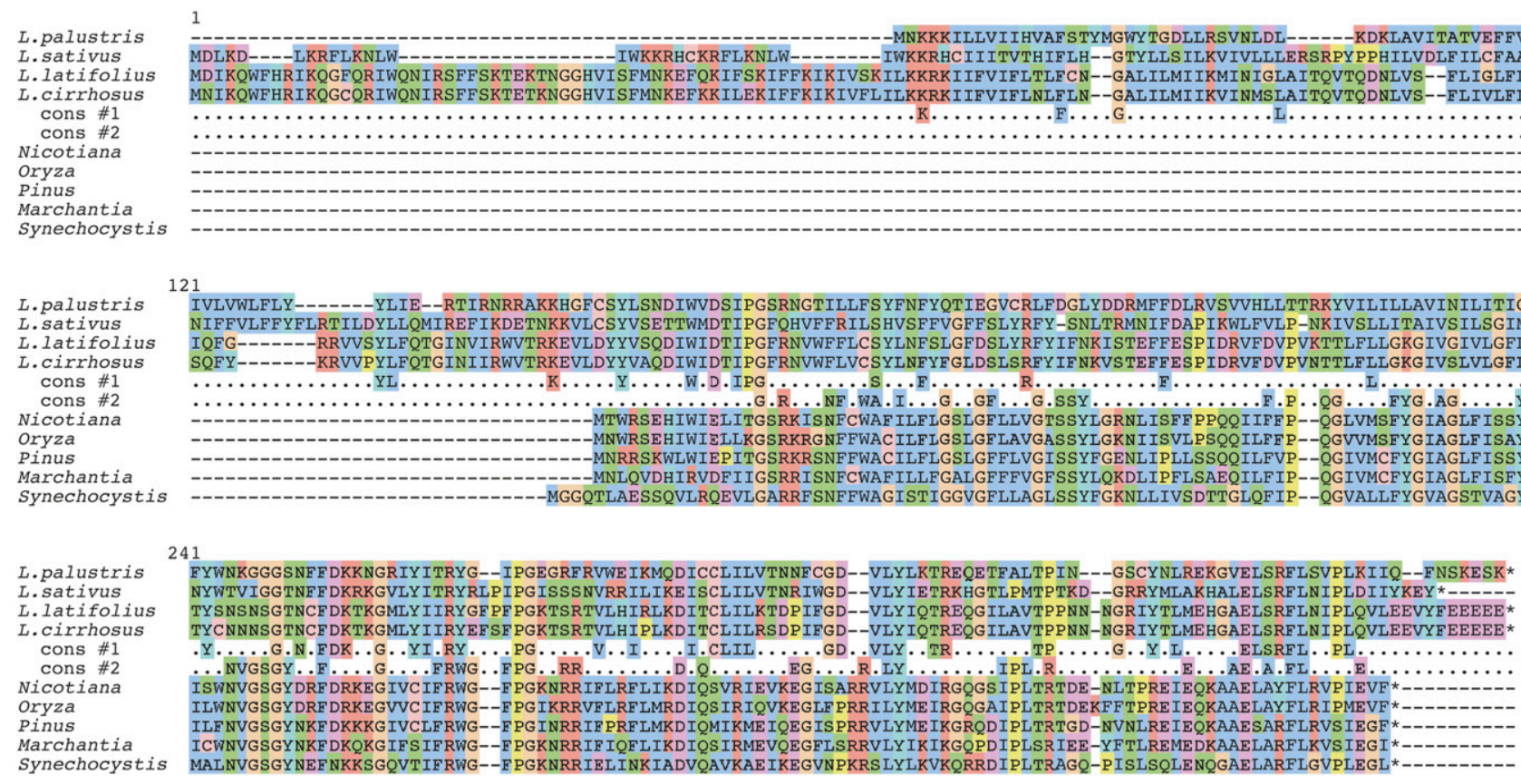

Figure 2. Alignments of Ycf4 protein sequences from four Lathyrus species, four diverse land plants, and the cyanobacterium Synechocystis. Cons \#1 shows residues that are absolutely conserved among the four Lathyrus species. Cons \#2 shows residues that are absolutely conserved among Nicotiana tabacum, Oryza sativa, Pinus thunbergii, Marchantia polymorpha, and Synechocystis species PCC 6803. The alignment was made using MUSCLE as implemented in SeaView (Gouy et al. 2010) with default coloring of conservative amino acid substitution groups.

(Supplemental Fig. S3). Both of these genomes lack the IR. They have rearrangements of gene order relative to the ancestral angiosperm order, as represented by tobacco, and also relative to each other. The gene order in P. sativum can be obtained from the tobacco order by eight inversion steps (Palmer et al. 1988), beginning with a $50-\mathrm{kb}$ inversion that is shared by most legumes and that placed $r p s 16$ beside $a c c D$. The first three inversions occurred before the separation of the lineages giving rise to P. sativum and L. sativus, after which there were five more inversions specific to $P$. sativum, and three more inversions specific to L. sativus (Supplemental Fig. S3). None of the inversions in P. sativum or L. sativus is shared with the highly rearranged cpDNA of $T$. subterraneum (Cai et al. 2008), other than the initial 50-kb inversion (Supplemental Fig. S3E).

The L. sativus genome sequence shows that it shares four gene losses that have already been reported in $P$. sativum: infA, rps16, rpl22, and rpl23 (Gantt et al. 1991; Nagano et al. 1991a,b; Millen et al. 2001); whereas L. sativus ycf4 is intact. The status of rpl23 in P. sativum has been unclear because it contains a 190-bp

Table 1. Sequence divergence in cpDNA regions compared among Lathyrus species

\begin{tabular}{|c|c|c|c|c|c|c|c|c|c|}
\hline \multirow[b]{2}{*}{ Sequence } & \multirow[b]{2}{*}{ Sites $^{\mathrm{a}}$} & \multicolumn{2}{|c|}{ L. palustris vs. L. Iatifolius } & \multicolumn{2}{|c|}{ L. palustris vs. L. sativus } & \multicolumn{2}{|c|}{ L. odoratus vs. L. Iatifolius } & \multicolumn{2}{|c|}{ L. cirrhosus vs. L. Iatifolius } \\
\hline & & $d_{\mathrm{N}} / d_{\mathrm{s}}$ & $d_{S} \pm S E(\%)$ & $d_{N} / d_{s}$ & $d_{\mathrm{S}} \pm \mathrm{SE}(\%)$ & $d_{N} / d_{s}$ & $d_{S} \pm S E(\%)$ & $d_{\mathrm{N}} / d_{\mathrm{S}}$ & $d_{\mathrm{S}} \pm \mathrm{SE}(\%)$ \\
\hline ycf4 & 109 & 0.362 & $152.2 \pm 52.6$ & 0.520 & $108.4 \pm 23.7$ & NA & NA & 0.805 & $4.8 \pm 2.2$ \\
\hline$a c c D$ & 112 & 0.677 & $7.1 \pm 2.7$ & 0.255 & $13.3 \pm 3.7$ & 1.399 & $2.3 \pm 1.5$ & $\infty$ & $0.0 \pm 0.0$ \\
\hline cemA & 150 & 1.723 & $1.4 \pm 1.0$ & 2.971 & $1.4 \pm 1.0$ & 0.951 & $0.7 \pm 0.7$ & $\infty$ & $0.0 \pm 0.0$ \\
\hline$r b c L$ & 200 & 0.149 & $3.6 \pm 1.4$ & 0.130 & $2.0 \pm 1.0$ & ND & ND & 0.000 & $0.5 \pm 0.5$ \\
\hline matK & 176 & 0.384 & $6.5 \pm 2.0$ & 0.550 & $5.4 \pm 1.8$ & 0.260 & $2.9 \pm 1.3$ & ND & ND \\
\hline Sequence & Sites & \multicolumn{2}{|c|}{ Kimura's $K \pm \mathrm{SE}(\%)$} & \multicolumn{2}{|c|}{ Kimura's $K \pm \mathrm{SE}(\%)$} & \multicolumn{2}{|c|}{ Kimura's $K \pm \mathrm{SE}(\%)$} & \multicolumn{2}{|c|}{ Kimura's $K \pm$ SE (\%) } \\
\hline $\begin{array}{c}r b c L-a t p B \\
\text { spacer }\end{array}$ & 747 & \multicolumn{2}{|r|}{$3.9 \pm 0.7$} & \multicolumn{2}{|r|}{$4.1 \pm 0.8$} & \multicolumn{2}{|r|}{ ND } & \multicolumn{2}{|c|}{$0.4 \pm 0.2$} \\
\hline $\begin{array}{l}\text { trnF-trnL } \\
\text { spacer }^{\text {b }}\end{array}$ & 475 & \multicolumn{2}{|r|}{$3.0 \pm 0.8$} & \multicolumn{2}{|r|}{$3.7 \pm 0.9$} & \multicolumn{2}{|r|}{$2.3 \pm 0.7$} & \multicolumn{2}{|r|}{ ND } \\
\hline $\begin{array}{c}\text { trnS-trnG } \\
\text { spacer }^{\text {b }}\end{array}$ & 616 & \multicolumn{2}{|r|}{$2.7 \pm 0.7$} & \multicolumn{2}{|r|}{$4.3 \pm 0.8$} & \multicolumn{2}{|r|}{$2.5 \pm 0.6$} & \multicolumn{2}{|r|}{ ND } \\
\hline
\end{tabular}

For protein-coding genes the synonymous divergence $\left(d_{S}\right)$, its standard error $(\mathrm{SE})$, and the nonsynonymous-to-synonymous ratio $\left(d_{\mathrm{N}} / d_{\mathrm{S}}\right.$, also called $\left.\omega\right)$ are shown. For intergenic regions, divergence $(K)$ was calculated using Kimura's two-parameter method. NA, Not applicable (gene not present); ND, not determined.

${ }^{a}$ Average number of sites compared across the reported species pairs. The $y c f 4, a c c D$, cemA, and $r b c L$ comparisons are all not full-length. For $y c f 4$, only the relatively conserved section between position 164 in Figure 2 and the $C$ terminus was compared.

${ }^{b}$ Sequence data from Kenicer et al. (2005). 


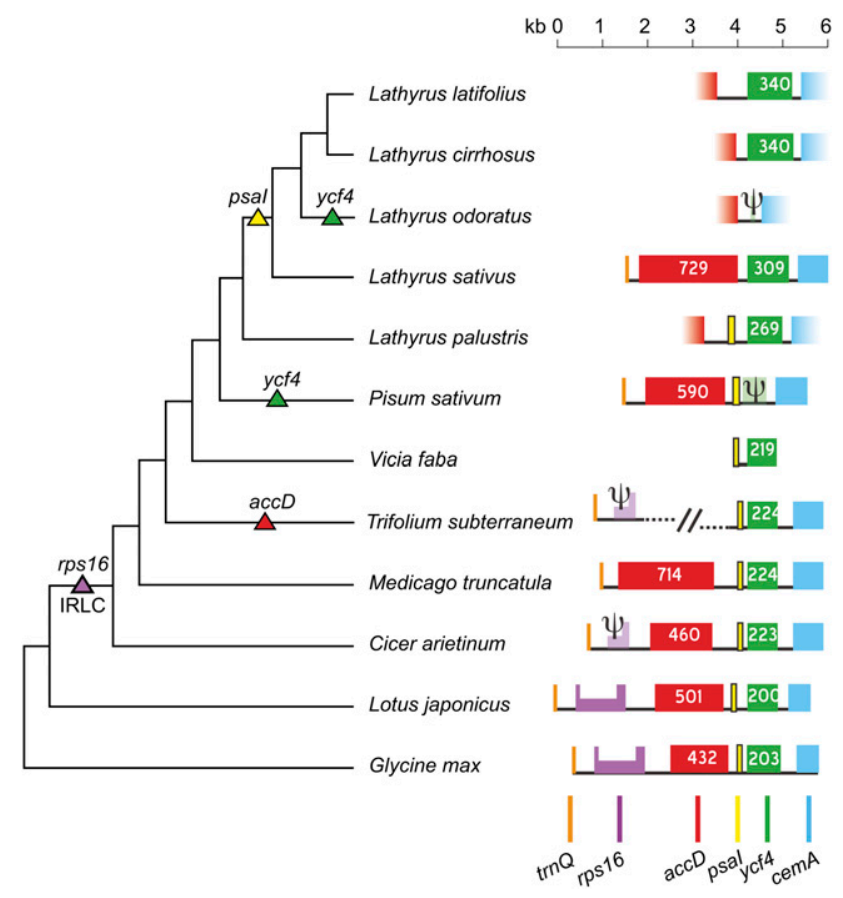

Figure 3. Gene organization around the $y c f 4$ locus in some legumes. Triangles indicate evolutionary losses of the indicated genes. Numbers indicate the numbers of codons in $a c c D$ and $y c f 4$ genes. Psi symbols denote pseudogenes. All genes are transcribed from left to right. Fading colors denote genes that were not completely sequenced. The half-height region in rps 16 represents an intron. The slash marks indicate a genomic rearrangement in $T$. subterraneum (Cai et al. 2008). The topology of the phylogenetic tree (not drawn to scale) is from Asmussen and Liston (1998), Wojciechowski et al. (2004), and Kenicer et al. (2005).

frameshifting insert close to the normal 3' end (Nagano et al. 1991b), but in L. sativus the same insert is present and more than half of rpl23 is missing, so we infer that $r p l 23$ is a pseudogene in both species. In addition, these two species differ by the absence of psaI in L. sativus, and of $y c f 4$ in P. sativum. As well as the gene losses, $P$. sativum and L. sativus both lack two of the 21 introns normally found in angiosperm cpDNA-the first intron of $c l p P$, and the cisintron of rps12. These intron losses were reported previously as part of a survey that showed their occurrence at about the time of origin of the IRLC clade (Jansen et al. 2008).

Legume chloroplast genomes have long been thought to contain more repetitive sequences than other cpDNAs (e.g., Saski et al. 2005), and this is confirmed by dot-matrix analysis. Using a cutoff of 28 matching bases per 30-bp window, there are very few repeated sequences of this size in the tobacco and spinach chloroplast genomes other than the IR and some similarities among group II introns and among iso-accepting tRNA genes (Supplemental Fig. S4). However in P. sativum, L. sativus, and Lotus japonicus (as a representative IR-containing legume), it is striking that there are many tandem or near-tandem repeats (i.e., dots near the main diagonal in Supplemental Fig. S4), and the region around $y c f 4$ stands out as particularly repetitive.

\section{Sites of gene loss coincide with a mutation hotspot}

We measured synonymous divergence in each protein-coding gene between the $P$. sativum and $L$. sativus chloroplast genomes using $d_{\mathrm{S}}$ (black circle symbols in Fig. 4), calculated by the yn00 program (Yang 2007). For most loci, the divergence between these species is less than 0.1 substitutions per site (median $d_{\mathrm{S}}=0.055$ synonymous substitutions per site). Ycf4 cannot be included directly in this comparison because it is absent from $P$. sativum cpDNA, so instead, for $y c f 4$ in Figure 4 we have plotted the $d_{\mathrm{S}}$ value between $L$. palustris and L. sativus, which is 20-fold higher (1.084) than the median even though the comparison is over a shorter divergence time. We observed even higher $d_{\mathrm{S}}$ values in comparing ycf4 between L. palustris and L. cirrhosus (1.481) or L. latifolius (1.522). Similarly, psaI is missing from L. sativus cpDNA so instead we compared $P$. sativum psaI to L. palustris psaI and found $d_{\mathrm{S}}=$ 0.580 , which again is much higher than the genome average for $P$. sativum versus $L$. sativus ( 0.055$)$. For $a c c D$ we compared only the regions of the gene that could be reliably aligned between $P$. sativum and L. sativus, and obtained a $d_{\mathrm{S}}$ value $(0.212)$ that is 3.8 times the genome average. This spike in local $d_{\mathrm{S}}$ values is matched by a local increase in divergence in the intergenic regions near the $y c f 4$ and accD loci (all compared between P. sativum and L. sativus using Kimura's $K$; open symbols in Fig. 4).

The very high level of synonymous substitution in $y c f 4$ made us question whether the mutational process at this locus might somehow be different than elsewhere in the genome. We investigated this possibility by sequencing regions of cpDNA from $L$. latifolius and L. cirrhosus (Fig. 3), two species that are evidently very closely related because there is only 1 nucleotide (nt) substitution between their $r b c L$ genes, and only three substitutions in the atpB$r b c L$ intergenic spacer (Fig. 5). There are only two differences out of $1256 \mathrm{bp}$ in the combined partial $a c c D$ and cem $A$ sequences obtained from these species, compared with 56 differences in the 1023-bp-long $y c f 4\left(d_{\mathrm{S}}=0.048, d_{\mathrm{N}}=0.039\right)$. Most strikingly, there are 19 differences (10\% divergence) in the spacer between $a c c D$ and $y c f 4$. This spacer (from which psaI has been lost) is 238 bp in $L$. cirrhosus, most of which can be aligned to L. latifolius, but in $L$. latifolius the spacer has expanded to $648 \mathrm{bp}$ due to the presence of multiple tandem repeat sequences comprising a 57-bp repeat unit (six complete and three partial copies) and a 67-bp repeat unit (two complete and one partial copy) (Supplemental Fig. S5). These results show that a region of $\sim 1500 \mathrm{bp}$ in these Lathyrus genomes, extending through the $a c c D-y c f 4$ spacer and most if not all of $y c f 4$ itself, is a hotspot with a mutation rate that is dramatically higher than in the rest of the genome. Despite this high mutation rate, the types of nucleotide substitution occurring in the $y c f 4$ region do not seem particularly biased, with an overall transition/transversion ratio of 0.9 (Fig. 5).

There also appears to be a smaller second peak of divergence values in the region around the genes rpl14 and $r p s 8$ (Fig. 4), which is the site from which infA was lost in an early ancestor of Fabales and Cucurbitales (Millen et al. 2001). We found that sites of gene loss coincide with fast-evolving intergenic regions more often than expected by chance: Five of the six most divergent intergenic regions between $P$. sativum and $L$. sativus are also the sites of five of their six gene losses ( $y c f 4, p s a I, r p s 16$, infA, rpl22; $P=2 \times 10^{-6}$ by the hypergeometric test).

\section{Mutation rate in ycf4 exceeds the rate in the nuclear genome}

Early work on rates of nucleotide substitution in plant genomes concluded that the synonymous substitution rate (assumed to be equal to the mutation rate) is about four times higher in plant nuclear genomes than in the single-copy regions of chloroplast genomes (Wolfe et al. 1987, 1989; Gaut 1998; Muse 2000). Given the heterogeneity of synonymous rates seen within the Lathyrus

\section{Genome Research www.genome.org}




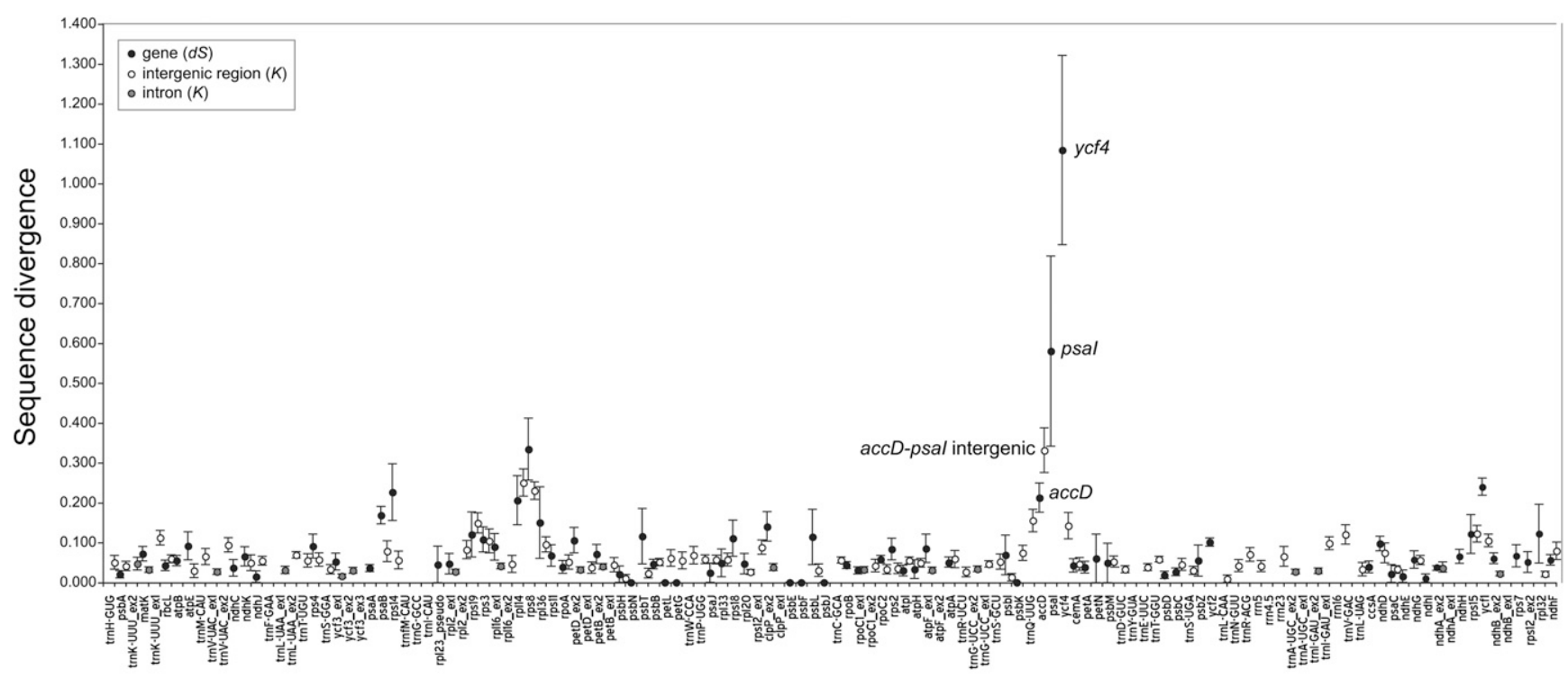

\section{Genes in order in L. sativus chloroplast genome}

Figure 4. Sequence divergence between the $P$. sativum and $L$. sativus chloroplast genomes. The $x$-axis lists genes or exons in the order in which they occur in the $L$. sativus genome. Black filled circles show $d_{S}$ (number of synonymous substitutions per synonymous site) for each orthologous protein gene pair, calculated using yn00 (Yang 2007). White and gray filled circles show divergence ( $K$ ) for each intergenic region or intron, respectively, calculated by Kimura's two-parameter method (Kimura 1983). Vertical bars, $d_{\mathrm{S}}$ or $K \pm 1 \mathrm{SE}$. Because $y c f 4$ is a pseudogene in $P$. sativum and psal is not present in $L$. sativus, the $d_{\mathrm{S}}$ value plotted for $y c f 4$ is for a comparison between $L$. sativus and $L$. palustris, and the $d_{\mathrm{S}}$ value plotted for $p s a l$ is for a comparison between $P$. sativum and $L$. palustris (see text). No divergence values are plotted for intergenic regions that are not flanked by the same genes in the two species or that are shorter than $100 \mathrm{bp}$.

chloroplast genomes, we wondered how these rates compared with the rate in the nuclear genome. Relatively few nuclear genes have been sequenced from Lathyrus species, so we generated new expressed sequence tag (EST) data from Lathyrus odoratus (sweetpea; see below) and identified putatively orthologous nuclear genes between these and database sequences from $P$. sativum. Among 56 putative orthologs, the median $d_{\mathrm{S}}$ is 0.131 (Supplemental Table S2), which is 2.4 times higher than the median $d_{\mathrm{S}}(0.055)$ for chloroplast genes compared between $P$. sativum and $L$. sativus. Thus in comparisons between Lathyrus and P. sativum, as in other flowering plant comparisons, the synonymous divergence in most parts of the chloroplast genome is lower than in the nuclear genome. The synonymous divergence in $y c f 4$, however, is at least 10 times greater than in the nuclear genome (the ratios of the $d_{\mathrm{S}}$ values given above, $1.084 / 0.131=8.3$ and $1.522 / 0.131=11.6$, are underestimates of the actual ratio because the numerators involve a shorter divergence time).

\section{Transfer of Trifolium accD to the nucleus}

We suspect that $y c f 4$ and $p s a I$ have been transferred to the nuclear genome in the Lathyrus species that lack them in cpDNA, because these species are fully photosynthetic and must have a functional photosystem I. However, we were unable to find nuclear copies of these genes. We made numerous unsuccessful attempts (see Methods) to amplify $y c f 4$ and psaI by PCR from genomic DNA of $L$. odoratus (which lacks both of them in its cpDNA and has a smaller $y c f 4$ pseudogene than P. sativum). We then made cDNA from young green leaves of $L$. odoratus and sequenced 8702 ESTs. None of the ESTs were derived from a nuclear $y c f 4$ or psaI, even though we did find ESTs corresponding to seven of the nine other nuclear-encoded subunits of photosystem I (Jolley et al. 2005), and to the older nuclear-transferred genes infA and $r p l 22$. Psal is a very small protein (34-40 amino acids) that is conserved between cyanobacteria and land plants and is physically located toward the exterior of photosystem I in P. sativum, where it interacts strongly with PsaH (Jolley et al. 2005; Amunts et al. 2007). It seems unlikely that photosystem I in Lathyrus could function efficiently without PsaI, although tobacco plants with a psaI knockout do not show a mutant phenotype under standard growth conditions (MA Schöttler and R Bock, pers. comm.). Most of the small membranespanning subunits of photosystem I appear to be nonessential, and knockout lines do not display visible mutant phenotypes (Varotto et al. 2002; Jensen et al. 2007; Schöttler et al. 2007). However, the loss of individual small membrane-spanning subunits usually affects the assembly of other subunits and results in lower

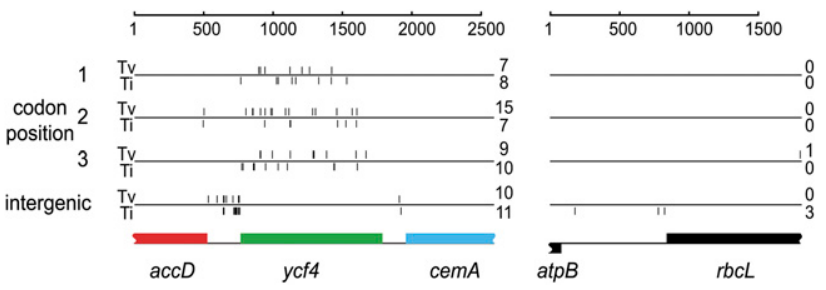

Figure 5. Sequence divergence between L. latifolius and $L$. cirrhosus in the $a c c D-y c f 4-c e m A$ region (left) and the $a t p B-r b c L$ region (right). Vertical tickmarks indicate the locations of each nucleotide substitution, categorized according to whether it occurs at codon position 1,2 , or 3 ; or in intergenic DNA; and as a transversion (Tv; tickmarks above the horizontal lines) or a transition (Ti; tickmarks below the horizontal line). The total numbers of each type of substitution are shown on the right. Supplemental Figure $\mathrm{S} 5$ shows the nucleotide sequence alignment summarized in the left panel. 
efficiencies of excitation transfer and electron transfer (Varotto et al. 2002; Jensen et al. 2007; Schöttler et al. 2007), which would be evolutionarily deleterious. The only other known cases of loss of psaI from plastid DNA are in the parasitic species Cuscuta gronovii and Cuscuta obtusiflora which have reduced levels of photosynthesis but retain all other photosynthesis genes (Funk et al. 2007; McNeal et al. 2007), and in the nonphotosynthetic parasite Epifagus (Wolfe et al. 1992).

Although we have direct evidence for association between gene losses and a mutation hotspot only in the genus Lathryus, it is intriguing that other species in the IRLC legume clade show evolutionary losses of other genes that neighbor $y c f 4$ and psaI (Fig. 3). The loss of rps16 in the common ancestor of the IRLC clade can be explained in terms of gene substitution by the nuclear gene for mitochondrial RPS16, as already demonstrated for Medicago (Ueda et al. 2008), and so does not necessitate a gene transfer to the nucleus. Rps16 has been lost on multiple independent occasions during land plant evolution (Supplemental Table S1; Ohyama et al. 1986; Tsudzuki et al. 1992; Ueda et al. 2008), so it is possible that its multiple losses in legumes are simply the result of relatively easy and/or early substitution by the mitochondrial gene.

The other IRLC legume gene loss in the neighborhood of $y c f 4$ and psaI is the loss of $a c c D$ in Trifolium (Fig. 3). AccD codes for a subunit of acetyl-CoA carboxylase, which functions in lipid synthesis and is an essential chloroplast gene in tobacco (Kode et al. 2005). The loss in Trifolium is one of five separate known instances of loss of $a c c D$ in angiosperm cpDNAs (Supplemental Table S1). In grass species-the only case that has been studied in detail-the prokaryotic multisubunit carboxylase in the plastid has been completely replaced by a nuclear-encoded single-chain carboxylase of eukaryotic ancestry (Konishi et al. 1996; Gornicki et al. 1997). We identified an evolutionary transfer of $a c c D$ to the nucleus in Trifolium. Using high-throughput EST sequence data from Trifolium repens (white clover), we found a cDNA structure consisting of a fusion between a gene for plastid lipoamide dehydrogenase (LPD2) and accD (Supplemental Fig. S6A-D). We confirmed the presence of a fused mRNA by reverse transcriptase PCR and Sanger sequencing (Supplemental Fig. S6E).

In plastids, lipoamide dehydrogenase is a component of pyruvate dehydrogenase, a complex that makes acetyl-CoA (Lutziger and Oliver 2000; Drea et al. 2001). The T. repens nuclear transcript codes for a predicted protein of 805 amino acids, with residues 1-512 (including a transit peptide) derived from $L P D 2$ and residues 513-805 derived from $a c c D$. By comparison to the known genomic structures of $L P D$ genes in M. truncatula, we infer that in T. repens the $a c c D$ sequence has replaced the final two exons (exons 14 and 15 ) of its LPD2 gene, with the point of fusion occurring at the third codon of exon 14 . We did not find any evidence for alternative splicing of the LPD2-accD fusion to form two products, as occurs with the SOD-rpl32 fusion in mangrove trees (Cusack and Wolfe 2007). The fusion to $a c c D$ probably rendered LPD2 unable to code for functional lipoamide dehydrogenase, because the fusion protein lacks some conserved residues normally provided by exons 14 and 15 , but $T$. repens retains and expresses a paralogous gene LPD1 that also codes for plastid lipoamide dehydrogenase (Supplemental Fig. S6A). We found the transferred gene in T. repens, but we presume that the transfer is shared by other Trifolium species, including the two that have been demonstrated to have no $a c c D$ in their cpDNAs (T. subterraneum and Trifolium pratense) (Doyle et al. 1995; Cai et al. 2008). We also found database ESTs for a nuclear accD in $T$. pratense (red clover), but they are too short to confirm that this species also has the $L P D 2-a c c D$ fusion. Phylogenetic analysis indicates that the $T$. repens and $T$. pratense nuclear sequences have a monophyletic origin and that the transfer of $a c c D$ to the nucleus occurred within the IRLC clade (Supplemental Fig. S6F), consistent with the change in LPD2 gene structure that occurred after Trifolium diverged from Medicago (Supplemental Fig. S6A). The Trifolium nuclear $a c c D$ gene is transcribed in both T. repens and T. pratense, is predicted to have a functional transit peptide in T. repens (TargetP cTP score 0.976) (Emanuelsson et al. 2000), and shows evidence of selection to maintain its AccDcoding function $\left(d_{\mathrm{N}} / d_{\mathrm{S}}=0.26\right.$ between $T$. repens and $T$. pratense in the $a c c D$ region of the transcript). Moreover, the Trifolium nuclear mRNAs code for a leucine residue at a site that undergoes an essential Ser $\rightarrow$ Leu mRNA edit in P. sativum plastids (Supplemental Fig. S6D; Sasaki et al. 2001; Inada et al. 2004).

\section{Discussion}

The genomic region around $y c f 4$ in Lathyrus is a dramatic hotspot for point mutations. It is difficult to quantify the factor by which its mutation rate is increased relative to the rest of the genome, but comparisons of synonymous site divergence indicate an increase of at least 20-fold, both in comparisons between P. sativum and L. sativus (Fig. 4) and among Lathyrus species (Table 1). Between L. latifolius and L. cirrhosus, the increase may be even greater (Fig. 5; Table 1). Even a 20 -fold mutation rate increase only goes partway toward explaining how the protein sequence divergence between $L$. palustris and $L$. cirrhosus (with a divergence time of $<10 \mathrm{Myr}$ ) (Kenicer et al. 2005) exceeds that between other angiosperms and cyanobacteria (separated by $>1000 \mathrm{Myr}$ ); a relaxation of selective constraints on the Ycf4 protein in legumes must be involved too. Although there have been previous reports that the variance of synonymous substitution rates among genes in many eukaryotic genomes is greater than expected by chance (e.g., Baer et al. 2007; Fox et al. 2008), there are few if any precedents for the phenomenon that we describe here-a sharply localized mutation rate acceleration of great magnitude in one specific region of a genome. The existence of the hotspot violates the common assumption that the point mutation rate is approximately constant in all regions of the same genome (Kimura 1983), which underpins the silent molecular clock hypothesis (Ochman and Wilson 1987). Our results bear some similarities to the "mutation showers" (transient localized hypermutation events) that have been found in some studies on the genomic distribution of spontaneous mutations (Drake 2007; Wang et al. 2007; Nishant et al. 2009). As well as being a mutation hotspot, $y c f 4$ and its neighbors also appear to be a hotspot for the formation and turnover of minisatellite sequences in Lathyrus.

The previous study most relevant to our findings is that of Erixon and Oxelman (2008), who reported somewhat similar results for the chloroplast clpP gene in Silene and Oenothera species. For some interspecies comparisons in their study, both $d_{\mathrm{N}}$ and $d_{\mathrm{S}}$ were elevated in clpP compared with other chloroplast genes, although the $d_{\mathrm{S}}$ elevations were at most fivefold for $c l p P$, compared with at least 20 -fold for $y c f 4$ in Lathyrus. Also, insertions of repetitive amino acid sequence regions occurred in some of the fastevolving taxa. Locus-specific rate accelerations affecting both $d_{\mathrm{N}}$ and $d_{\mathrm{S}}$ were reported in cpDNA of Geraniaceae, but in this case, the accelerations occurred in numerous genes (Guisinger et al. 2008). In all IR-containing cpDNAs, the synonymous rate is higher in single-copy genes than in IR-located genes, probably due to a copynumber effect during DNA repair (Wolfe et al. 1987; Birky and Walsh 1992; Perry and Wolfe 2002). Dramatic accelerations of 
synonymous rates have been found in the mitochondrial genomes of some plants, such as Plantago, Pelargonium, and certain Silene species (Cho et al. 2004; Parkinson et al. 2005; Mower et al. 2007; Sloan et al. 2009). Most of these mitochondrial accelerations appear to affect all genes in the genome similarly, but among-gene rate heterogeneity was found within the mtDNAs of a few species (Mower et al. 2007), including a 40-fold difference in synonymous rates between atp9 and three other mitochondrial genes in Silene (Sloan et al. 2009). Because plant mitochondrial genomes are relatively large and do not show much gene order conservation, most studies have only examined individual genes so the sizes of the genomic regions affected by rate acceleration are not known.

Apart from these organellar examples, there are very few precedents for a mutation rate change that is so pronounced over such a short physical distance. One early study (Martin and Meyerowitz 1986) reported a 2-kb region of noncoding DNA near the glue gene cluster of three Drosophila species, which contained an abrupt boundary between a conserved region and a nonconserved region with a 10-fold elevated substitution rate, but this report has not been followed up with more extensive analyses based on complete genome sequence data. An abrupt boundary of evolutionary rates also occurs on the mammalian X chromosome at the junction between the pseudoautosomal region and the $\mathrm{X}$-specific region. The pseudoautosomal part of the gene Fxy, which spans this junction in laboratory mice, has a synonymous rate about 60 times faster than the X-specific part of the gene, probably because the high recombination rate in the pseudoautosomal part leads to high levels of biased gene conversion (Perry and Ashworth 1999; Duret and Galtier 2009).

Is the chloroplast hypermutation phenomenon unique to Lathyrus? At present, Lathyrus is the only legume genus for which we have extensive sequence data from more than one species, so we are unable to say whether the same hotspot is present in legumes outside this genus. Therefore the only gene losses we can potentially attribute directly to hypermutation are those of $y c f 4$ in L. odoratus and of psaI in the ancestor of four Lathyrus species. Ycf4 is also evolving fast in Desmodium and has been lost in three species of that genus. The losses of $y c f 4$ in P. sativum, of accD in Trifolium, and the older loss of rps16 in the ancestor of the IRLC clade are suggestive, but we have no direct evidence that these loci were fastevolving prior to the gene losses. It is possible that a hotspot has existed throughout legume evolution and was the cause of the $y c f 4$ acceleration seen in the common ancestor of Millettioids, Robinioids, and the IRLC (Fig. 1) but that the exact location of the hotspot (and its associated tandem repeat sequences) has varied somewhat among lineages, affecting $y c f 4$ in some taxa, but accD or psaI in others. We do not know the molecular basis for the increases in either the point mutation rate or the length mutation rate, but we speculate that they might be connected. We suggest that a correlation between the two rates could develop if, for some reason, the genomic region around $y c f 4$ was subject to repeated DNA breakage and repair (cf. Guisinger et al. 2008; Yang et al. 2008). In this regard, it is interesting to note that only a few angiosperm species have cpDNAs that are highly rearranged relative to the canonical gene order, but among these, there are several independent lineages that are both highly rearranged and contain rapidly-evolving protein genes (Jansen et al. 2007). These lineages include Jasminum (acceleration of accD; Lee et al. 2007), Silene (acceleration of $c l p P$; Erixon and Oxelman 2008), and now Lathyrus (acceleration of $y c f 4$ ). The phylogenetic diversity of these lineages suggests that hypermutable regions may exist in other angiosperm cpDNAs, and our findings may go some way toward explaining the apparent bursts of organelle-to-nucleus gene transfer seen in some angiosperms.

It is likely that many factors dictate whether a gene can be lost from an organelle genome. One property that is common to the gene transfer and gene substitution processes is that they both involve a phase during which the organelle gene and the nuclear gene coexist in the same species (Timmis et al. 2004). Analogous to a gene duplication, this two-gene phase can be resolved either by losing the organelle copy (resulting in a successful transfer of function) or by losing the nuclear copy (restoring the status quo). Intermediates in this process, and sister lineages where the twogene phase was resolved in opposite ways, have been identified (Adams et al. 1999). Brandvain and Wade (2009) have shown theoretically that the ratio between the point mutation rates in the organelle and nuclear copies has a profound influence on the direction in which the two-gene phase is resolved. If the organelle mutation rate is lower than the nuclear mutation rate, as is true for most plant mitochondrial and chloroplast genes, then gene transfer will not occur unless there is a benefit to relocating the gene. By contrast, if the organelle rate exceeds the nuclear rate, then gene transfer is predicted to occur even in the absence of any benefit (Brandvain and Wade 2009). Therefore, in a genome such as Lathyrus cpDNA, in which the mutation rate exceeds the nuclear rate only in one hypermutable region, we should expect to see more transfers, substitutions, or losses of genes from the hypermutable region than from the rest of the genome. This argument provides a plausible explanation for the losses of $y c f 4$ and psaI seen in some Lathyrus species and, perhaps more generally, for the cluster of losses from the rps16-accD-psaI-ycf4 region seen in other legume cpDNAs.

\section{Methods}

\section{Plant material}

Seeds of Lathyrus sativus (cv. Cicerchia Marchigiana) were purchased from B\&T World Seeds. Seeds of L. cirrhosus (accession no. LAT17) were obtained from the Leibniz Institute of Plant Genetics and Crop Plant Research. Other Lathyrus species were purchased from Thompson \& Morgan. Additional sequencing of $P$. sativum cpDNA was done using cv. Feltham First.

\section{Nucleotide sequencing}

The P. sativum (pea) chloroplast genome sequence was completed by S.A. and J.C.G. using the chain termination method (Sanger et al. 1977) with fluorescent dideoxynucleotides on PCR products amplified from cloned PstI fragments (Palmer and Thompson 1981), from cpDNA extracted from isolated chloroplasts, or from total DNA extracted from shoots of 8-d-old seedlings. Chloroplasts were isolated by the high-salt method (Bookjans et al. 1984), and DNA was extracted by the CTAB (hexadecyltrimethylammonium bromide) method (Milligan 1989). Previously published regions were not resequenced except at the borders or where there were discrepancies between publications. Newly sequenced regions were completed on both strands, and all the PstI sites used for cloning were confirmed by sequencing spanning PCR fragments. At the $y c f 4$ locus, there is a 2-bp deletion in the sequence reported by Nagano et al. (1991a), relative to the sequence reported by Smith et al. (1991), both of which were obtained from the same cloned 17.3-kb PstI fragment from P. sativum cv. Alaska. We confirmed that this 2-bp deletion exists, in both cv. Alaska and cv. Feltham First. This correction means that the reported ORF157 (Smith et al. 1991) does not exist. 
The L. sativus (grasspea) chloroplast genome sequence was determined by A.M.M., T.A.K., and K.H.W. Approximately 150 seeds were grown on soil in the greenhouse. Seedling shoots were harvested at $7 \mathrm{~d}$ post-germination, and cpDNA was prepared according to the method described by Milligan (1989) except that chloroplast lysis and cpDNA recovery procedures were modified. Chloroplasts were lysed by adding a $1 / 5$ volume of $10 \% \mathrm{CTAB}$ (Sigma-Aldrich) and heating for $20 \mathrm{~min}$ at $70^{\circ} \mathrm{C}$. This was followed by a chloroform extraction, treatment with RNaseA $(10 \mu \mathrm{g} / \mathrm{mL})$, and isopropanol precipitation of cpDNA. A plasmid library of nebulized fragments was constructed from $5 \mu \mathrm{g}$ of cpDNA by GATC-Biotech. The genome sequence was assembled from 1536 Sanger shotgun sequence reads with primer-walking to close gaps.

We tried unsuccessfully to amplify ycf4 and psaI by PCR from L. odoratus genomic DNA using 16 and 9 primer combinations, respectively, and a range of amplification conditions. These primers were designed based on amino acid residues conserved among known Fabaceae Ycf4 and PsaI proteins, but primer design for these genes is difficult due to the fast rate of $y c f 4$ evolution and the short length of psaI, as well as the high $\mathrm{A}+\mathrm{T}$ content of the region. To obtain EST data from $L$. odoratus, we isolated poly(A) mRNA from leaves of 3-d-old seedlings. A normalized cDNA library was constructed by GATC-Biotech, and the $3^{\prime}$ ends of 8702 cDNAs were sequenced by Agencourt Biosciences. ESTs were assembled into contigs, and putative orthologs between these contigs and $P$. sativum sequence data from GenBank were identified according the method of Sémon and Wolfe (2008).

The other new sequence data indicated in Figures 3 and 5 were generated by PCR amplification and sequencing (by primer walking) of at least three independent cloned products for each region. The cpDNA region that normally contains $y c f 4$ was PCR amplified from L. latifolius, L. cirrhosus, L. odoratus, and L. palustris using primers designed from the $P$. sativum accD (5'-AAACAGGCACAGG TCAASTAAATGG-3') and cemA (5'-GACGGAGATACACGATTTA AATAACG-3') genes. The atpB-rbcL region from $L$. latifolius, $L$. cirrhosus, and $L$. palustris was amplified with primers 5 '-TGRAAAA RCTACATCGAGTACCGGAGG-3' and 5'-TATGATCTCCACCAGA CATACG-3'. T. repens mRNA sequences coding for LPD1 and the $L P D 2-a c c D$ fusion gene were identified among 700,000 ESTs obtained by high-throughput pyrosequencing of flower, leaf, and stolon mRNA from the inbred line S (7S.4.6.3.3.4.4.10) (DM and SB, unpubl.) and assembled manually. The structure of the $L P D 2-a c c D$ junction was confirmed by reverse transcriptase-PCR from $T$. repens leaf mRNA (commercial variety Nusiral) and Sanger sequencing.

\section{Computational methods}

Sequence divergence for most analyses was calculated using yn00 from the PAML package (Yang 2007) for coding regions and Kimura's two-parameter method (Kimura 1983) for noncoding regions. Gene sequences were aligned by reverse-translation of ClustalW alignments of the corresponding protein sequences. Noncoding sequences were aligned using ClustalW with manual adjustment for regions around $y c f 4$. For the analysis in Figure 1 and Supplemental Figure S1, we first constructed a maximum likelihood phylogeny (in PAUP) from matK sequences using the HKY substitution model with a four category gamma rate distribution. The transition/transversion ratio and shape parameter were estimated iteratively until the topology converged. This analysis included legume $y c f 4$ sequences from Stefanovic et al. (2009; GenBank [http://www.ncbi.nlm.nih.gov/Genbank/] accession nos. EU717431-EU717464). The $d_{\mathrm{N}}$ and $d_{\mathrm{S}}$ branch lengths for the matK, $y c f 4$, and $r b c L$ trees were estimated based on the PAML/codeML free-ratio model, using the fixed topology obtained from the above
matK ML analysis. Dot-matrix plots were made using DNAMAN (http://www.lynnon.com) (Huang and Zhang 2004).

\section{Acknowledgments}

We thank Gavin Conant for help with Figure S3, Shusei Sato for Trifolium cDNA clones, Greg Kenicer for prepublication access to sequence data, and Ralph Bock for discussion. S.A. and J.C.G. thank Chris Maddren (Department of Genetics, University of Cambridge) for DNA sequencing. This study was supported by Science Foundation Ireland (K.H.W., T.A.K.), European Commission FP5 Plastid Factory (J.C.G., T.A.K.), US National Institutes of Health (J.D.P.), and the METACyt Initiative of Indiana University, funded in part through a major grant from the Lilly Endowment, Inc. (J.D.P., D.W.R.).

\section{References}

Adams KL, Palmer JD. 2003. Evolution of mitochondrial gene content: Gene loss and transfer to the nucleus. Mol Phylogenet Evol 29: 380-395.

Adams KL, Song K, Roessler PG, Nugent JM, Doyle JL, Doyle JJ, Palmer JD. 1999. Intracellular gene transfer in action: Dual transcription and multiple silencings of nuclear and mitochondrial cox2 genes in legumes. Proc Natl Acad Sci 96: 13863-13868.

Amunts A, Drory O, Nelson N. 2007. The structure of a plant photosystem I supercomplex at $3.4 \AA$ resolution. Nature 447: 58-63.

Asmussen CB, Liston A. 1998. Chloroplast DNA characters, phylogeny, and classification of Lathyrus (Fabaceae). Am J Bot 85: 387-401.

Baer CF, Miyamoto MM, Denver DR. 2007. Mutation rate variation in multicellular eukaryotes: Causes and consequences. Nat Rev Genet 8: 619-631.

Birky CW Jr, Walsh JB. 1992. Biased gene conversion, copy number, and apparent mutation rate differences within chloroplast and bacterial genomes. Genetics 130: 677-683.

Bookjans G, Stummann BM, Henningsen KW. 1984. Preparation of chloroplast DNA from pea plastids isolated in a medium of high ionic strength. Anal Biochem 141: 244-247.

Boudreau E, Takahashi Y, Lemieux C, Turmel M, Rochaix JD. 1997. The chloroplast $y c f 3$ and $y c f 4$ open reading frames of Chlamydomonas reinhardtii are required for the accumulation of the photosystem I complex. EMBO J 16: 6095-6104.

Brandvain Y, Wade MJ. 2009. The functional transfer of genes from the mitochondria to the nucleus: The effects of selection, mutation, population size and rate of self-fertilization. Genetics 182: 11291139.

Cai Z, Guisinger M, Kim HG, Ruck E, Blazier JC, McMurtry V, Kuehl JV, Boore J, Jansen RK. 2008. Extensive reorganization of the plastid genome of Trifolium subterraneum (Fabaceae) is associated with numerous repeated sequences and novel DNA insertions. J Mol Evol 67: 696-704.

Chateigner-Boutin AL, Small I. 2007. A rapid high-throughput method for the detection and quantification of RNA editing based on highresolution melting of amplicons. Nucleic Acids Res 35: e114. doi: 10.1093/nar/gkm640.

Cho Y, Mower JP, Qiu YL, Palmer JD. 2004. Mitochondrial substitution rates are extraordinarily elevated and variable in a genus of flowering plants. Proc Natl Acad Sci 101: 17741-17746.

Cusack BP, Wolfe KH. 2007. When gene marriages don't work out: Divorce by subfunctionalization. Trends Genet 23: 270-272.

Doyle JJ, Doyle JL, Palmer JD. 1995. Multiple independent losses of two genes and one intron from legume chloroplast genomes. Syst Bot 20: 272-294.

Drake JW. 2007. Too many mutants with multiple mutations. Crit Rev Biochem Mol Biol 42: 247-258.

Drea SC, Mould RM, Hibberd JM, Gray JC, Kavanagh TA. 2001. Tissuespecific and developmental-specific expression of an Arabidopsis thaliana gene encoding the lipoamide dehydrogenase component of the plastid pyruvate dehydrogenase complex. Plant Mol Biol 46: 705-715.

Drouin G, Daoud H, Xia J. 2008. Relative rates of synonymous substitutions in the mitochondrial, chloroplast and nuclear genomes of seed plants. Mol Phylogenet Evol 49: 827-831.

Duret L, Galtier N. 2009. Biased gene conversion and the evolution of mammalian genomic landscapes. Annu Rev Genomics Hum Genet 10: 285-311.

Emanuelsson O, Nielsen H, Brunak S, von Heijne G. 2000. Predicting subcellular localization of proteins based on their N-terminal amino acid sequence. J Mol Biol 300: 1005-1016. 
Erixon P, Oxelman B. 2008. Whole-gene positive selection, elevated synonymous substitution rates, duplication, and indel evolution of the chloroplast clpP1 gene. PLOS ONE 3: e1386. doi: 10.1371/ journal.pone.0001386.

Fox AK, Tuch BB, Chuang JH. 2008. Measuring the prevalence of regional mutation rates: An analysis of silent substitutions in mammals, fungi, and insects. BMC Evol Biol 8: 186. doi: 10.1186/1471-2148-8-186.

Funk HT, Berg S, Krupinska K, Maier UG, Krause K. 2007. Complete DNA sequences of the plastid genomes of two parasitic flowering plant species, Cuscuta reflexa and Cuscuta gronovii. BMC Plant Biol 7: 45. doi: 10.1186/1471-2229-7-45.

Gantt JS, Baldauf SL, Calie PJ, Weeden NF, Palmer JD. 1991. Transfer of rpl22 to the nucleus greatly preceded its loss from the chloroplast and involved the gain of an intron. EMBO J 10: 3073-3078.

Gaut BS. 1998. Molecular clocks and nucleotide substitution rates in higher plants. Evol Biol 30: $93-120$.

Gaut BS, Muse SV, Clegg MT. 1993. Relative rates of nucleotide substitution in the chloroplast genome. Mol Phylogenet Evol 2: 89-96.

Gornicki P, Faris J, King I, Podkowinski J, Gill B, Haselkorn R. 1997. Plastidlocalized acetyl-CoA carboxylase of bread wheat is encoded by a single gene on each of the three ancestral chromosome sets. Proc Natl Acad Sci 94: $14179-14184$

Gouy M, Guindon S, Gascuel O. 2010. SeaView version 4: A multiplatform graphical user interface for sequence alignment and phylogenetic tree building. Mol Biol Evol 27: 221-224.

Graur D, Li W-H. 1999. Fundamentals of molecular evolution. Sinauer, Sunderland, MA

Guisinger MM, Kuehl JV, Boore JL, Jansen RK. 2008. Genome-wide analyses of Geraniaceae plastid DNA reveal unprecedented patterns of increased nucleotide substitutions. Proc Natl Acad Sci 105: 18424-18429.

Guo X, Castillo-Ramirez S, Gonzales V, Bustos P, Fernandez-Vazquez JL, Santamaria RI, Arellano J, Cevallos MA, Davila G. 2007. Rapid evolutionary change of common bean (Phaseolus vulgaris L.) plastome and genomic diversification of legume chloroplasts. BMC Genomics $\mathbf{8}$ : 228. doi: 10.1186/1471-2164-8-228.

Huang Y, Zhang L. 2004. Rapid and sensitive dot-matrix methods for genome analysis. Bioinformatics 20: $460-466$.

Inada M, Sasaki T, Yukawa M, Tsudzuki T, Sugiura M. 2004. A systematic search for RNA editing sites in pea chloroplasts: An editing event causes diversification from the evolutionarily conserved amino acid sequence. Plant Cell Physiol 45: 1615-1622.

Jansen RK, Cai Z, Raubeson LA, Daniell H, Depamphilis CW, Leebens-Mack J, Muller KF, Guisinger-Bellian M, Haberle RC, Hansen AK, et al. 2007. Analysis of 81 genes from 64 plastid genomes resolves relationships in angiosperms and identifies genome-scale evolutionary patterns. Proc Natl Acad Sci 104: 19369-19374.

Jansen RK, Wojciechowski MF, Sanniyasi E, Lee SB, Daniell H. 2008. Complete plastid genome sequence of the chickpea (Cicer arietinum) and the phylogenetic distribution of $r p s 12$ and $c l p P$ intron losses among legumes (Leguminosae). Mol Phylogenet Evol 48: 1204-1217.

Jensen PE, Bassi R, Boekema EJ, Dekker JP, Jansson S, Leister D, Robinson C, Scheller HV. 2007. Structure, function and regulation of plant photosystem I. Biochim Biophys Acta 1767: 335-352.

Jolley C, Ben-Shem A, Nelson N, Fromme P. 2005. Structure of plant photosystem I revealed by theoretical modeling. J Biol Chem 280: 33627-33636.

Kato T, Kaneko T, Sato S, Nakamura Y, Tabata S. 2000. Complete structure of the chloroplast genome of a legume, Lotus japonicus. DNA Res 7: 323330.

Kenicer GJ, Kajita T, Pennington RT, Murata J. 2005. Systematics and biogeography of Lathyrus (Leguminosae) based on internal transcribed spacer and cpDNA sequence data. Am J Bot 92: 1199-1209.

Kim K-J, Lee H-L. 2004. Complete chloroplast genome sequences from Korean ginseng (Panax schinseng Nees). Comparative analysis of sequence evolution among 17 vascular plants. DNA Res 11: 247-261.

Kimura M. 1977. Preponderance of synonymous changes as evidence for the neutral theory of molecular evolution. Nature 267: 275-276.

Kimura M. 1983. The neutral theory of molecular evolution. Cambridge University Press, Cambridge, UK.

Kode V, Mudd EA, Iamtham S, Day A. 2005. The tobacco plastid accD gene is essential and is required for leaf development. Plant J 44: 237-244.

Konishi T, Shinohara K, Yamada K, Sasaki Y. 1996. Acetyl-CoA carboxylase in higher plants: Most plants other than gramineae have both the prokaryotic and the eukaryotic forms of this enzyme. Plant Cell Physiol 37: 117-122.

Lee HL, Jansen RK, Chumley TW, Kim KJ. 2007. Gene relocations within chloroplast genomes of Jasminum and Menodora (Oleaceae) are due to multiple, overlapping inversions. Mol Biol Evol 24: 1161-1180.

Lutziger I, Oliver DJ. 2000. Molecular evidence of a unique lipoamide dehydrogenase in plastids: Analysis of plastidic lipoamide dehydrogenase from Arabidopsis thaliana. FEBS Lett 484: 12-16.
Martin CH, Meyerowitz EM. 1986. Characterization of the boundaries between adjacent rapidly and slowly evolving genomic regions in Drosophila. Proc Natl Acad Sci 83: 8654-8658.

McNeal JR, Kuehl JV, Boore JL, Depamphilis CW. 2007. Complete plastid genome sequences suggest strong selection for retention of photosynthetic genes in the parasitic plant genus Cuscuta. BMC Plant Biol 7: 57. doi: 10.1186/1471-2229-7-57.

Millen RS, Olmstead RG, Adams KL, Palmer JD, Lao NT, Heggie L, Kavanagh TA, Hibberd JM, Gray JC, Morden CW, et al. 2001. Many parallel losses of infA from chloroplast DNA during angiosperm evolution with multiple independent transfers to the nucleus. Plant Cell 13: 645-658.

Milligan BG. 1989. Purification of chloroplast DNA using hexadecyltrimethylammonium bromide. Plant Mol Biol Rep 7: 144-149.

Milligan BG, Hampton JN, Palmer JD. 1989. Dispersed repeats and structural reorganization in subclover chloroplast DNA. Mol Biol Evol 6: 355368.

Mower JP, Touzet P, Gummow JS, Delph LF, Palmer JD. 2007. Extensive variation in synonymous substitution rates in mitochondrial genes of seed plants. BMC Evol Biol 7: 135. doi: 10.1186/1471-2148-7-135.

Muse SV. 2000. Examining rates and patterns of nucleotide substitution in plants. Plant Mol Biol 42: 25-43.

Nagano Y, Matsuno R, Sasaki Y. 1991a. Sequence and transcriptional analysis of the gene cluster trnQ-zfpA-psaI-ORF231-petA in pea chloroplasts. Curr Genet 20: $431-436$.

Nagano Y, Ishikawa H, Matsuno R, Sasaki Y. 1991b. Nucleotide sequence and expression of the ribosomal protein L2 gene in pea chloroplasts. Plant Mol Biol 17: 541-545.

Nishant KT, Singh ND, Alani E. 2009. Genomic mutation rates: What highthroughput methods can tell us. BioEssays 31: 912-920.

Ochman H, Wilson AC. 1987. Evolution in bacteria: Evidence for a universal substitution rate in cellular genomes. J Mol Evol 26: 74-86.

Ohyama K, Fukuzawa H, Kohchi T, Shirai H, Sano T, Sano S, Umesono K, Shiki Y, Takeuchi M, Chang Z, et al. 1986. Chloroplast gene organization deduced from complete sequence of liverwort Marchantia polymorpha chloroplast DNA. Nature 322: 572-574.

Onishi T, Takahashi Y. 2009. Effects of site-directed mutations in the chloroplast-encoded $y c f 4$ gene on photosystem I complex assembly in the green alga Chlamydomonas reinhardtii. Plant Cell Physiol 50: 17501760.

Ozawa SI, Nield J, Terao A, Stauber EJ, Hippler M, Koike H, Rochaix JD, Takahashi Y. 2009. Biochemical and structural studies of the large Ycf4photosystem I assembly complex of the green alga Chlamydomonas reinhardtii. Plant Cell 21: 2424-2442.

Palmer JD. 1985. Comparative organization of chloroplast genomes. Annu Rev Genet 19: 325-354.

Palmer JD, Thompson WF. 1981. Clone banks of the mung bean, pea and spinach chloroplast genomes. Gene 15: 21-26.

Palmer JD, Osorio B, Thompson WF. 1988. Evolutionary significance of inversions in legume chloroplast DNAs. Curr Genet 14: 65-74.

Palmer JD, Adams KL, Cho Y, Parkinson CL, Qiu YL, Song K. 2000. Dynamic evolution of plant mitochondrial genomes: Mobile genes and introns and highly variable mutation rates. Proc Natl Acad Sci 97: 69606966.

Parkinson CL, Mower JP, Qiu YL, Shirk AJ, Song K, Young ND, DePamphilis CW, Palmer JD. 2005. Multiple major increases and decreases in mitochondrial substitution rates in the plant family Geraniaceae. BMC Evol Biol 5: 73. doi: 10.1186/1471-2148-5-73.

Perry J, Ashworth A. 1999. Evolutionary rate of a gene affected by chromosomal position. Curr Biol 9: 987-989.

Perry AS, Wolfe KH. 2002. Nucleotide substitution rates in legume chloroplast DNA depend on the presence of the inverted repeat. J Mol Evol 55: 501-508.

Reverdatto SV, Beilinson V, Nielsen NC. 1995. The rps16, accD, psaI, ORF 203, ORF 151, ORF 103, ORF 229 and petA gene cluster in the chloroplast genome of soybean (PGR95-051). Plant Physiol 109: 338.

Sanger F, Nicklen S, Coulson AR. 1977. DNA sequencing with chainterminating inhibitors. Proc Natl Acad Sci 74: 5463-5467.

Sasaki Y, Kozaki A, Ohmori A, Iguchi H, Nagano Y. 2001. Chloroplast RNA editing required for functional acetyl-CoA carboxylase in plants. J Biol Chem 276: 3937-3940.

Saski C, Lee SB, Daniell H, Wood TC, Tomkins J, Kim HG, Jansen RK. 2005 Complete chloroplast genome sequence of Glycine max and comparative analyses with other legume genomes. Plant Mol Biol 59: 309-322.

Schöttler MA, Flugel C, Thiele W, Stegemann S, Bock R. 2007. The plastomeencoded PsaJ subunit is required for efficient photosystem I excitation, but not for plastocyanin oxidation in tobacco. Biochem J 403: 251-260.

Sémon M, Wolfe KH. 2008. Preferential subfunctionalization of slowevolving genes in Xenopus laevis. Proc Natl Acad Sci 105: 8333-8338.

Sloan DB, Oxelman B, Rautenberg A, Taylor DR. 2009. Phylogenetic analysis of mitochondrial substitution rate variation in the angiosperm tribe Sileneae. BMC Evol Biol 9: 260. doi: 10.1186/1471-2148-9-260. 
Smith AG, Wilson RM, Kaethner TM, Willey DL, Gray JC. 1991. Pea chloroplast genes encoding a $4 \mathrm{kDa}$ polypeptide of photosystem I and a putative enzyme of C1 metabolism. Curr Genet 19: 403-410.

Stefanovic S, Pfeil BE, Palmer JD, Doyle JJ. 2009. Relationships among phaseolid legumes based on sequences from eight chloroplast regions. Syst Bot 34: 115-128.

Stern DB, Goldschmidt-Clermont M, Hanson MR. 2010. Chloroplast RNA metabolism. Annu Rev Plant Biol 61: 125-155.

Sugiura M. 1992. The chloroplast genome. Plant Mol Biol 19: 149-168.

Timmis JN, Ayliffe MA, Huang CY, Martin W. 2004. Endosymbiotic gene transfer: Organelle genomes forge eukaryotic chromosomes. Nat Rev Genet 5: 123-135.

Tsudzuki J, Nakashima K, Tsudzuki T, Hiratsuka J, Shibata M, Wakasugi T, Sugiura M. 1992. Chloroplast DNA of black pine retains a residual inverted repeat lacking rRNA genes: nucleotide sequences of $\operatorname{trn} Q$, trnK, $p s b A$, trnI and trnH and the absence of rps16. Mol Gen Genet 232: 206-214.

Tsudzuki T, Wakasugi T, Sugiura M. 2001. Comparative analysis of RNA editing sites in higher plant chloroplasts. J Mol Evol 53: 327-332.

Ueda M, Fujimoto M, Arimura SI, Murata J, Tsutsumi N, Kadowaki KI. 2007. Loss of the rpl32 gene from the chloroplast genome and subsequent acquisition of a preexisting transit peptide within the nuclear gene in Populus. Gene 402: 51-56.

Ueda M, Nishikawa T, Fujimoto M, Takanashi H, Arimura SI, Tsutsumi N, Kadowaki KI. 2008. Substitution of the gene for chloroplast RPS16 was assisted by generation of a dual targeting signal. Mol Biol Evol 25: 15661575.

Varotto C, Pesaresi P, Jahns P, Lessnick A, Tizzano M, Schiavon F, Salamini F, Leister D. 2002. Single and double knockouts of the genes for photosystem I subunits G, K, and H of Arabidopsis. Effects on photosystem I composition, photosynthetic electron flow, and state transitions. Plant Physiol 129: 616-624
Wang J, Gonzalez KD, Scaringe WA, Tsai K, Liu N, Gu D, Li W, Hill KA, Sommer SS. 2007. Evidence for mutation showers. Proc Natl Acad Sci 104: $8403-8408$.

Wilde A, Hartel H, Hubschmann T, Hoffmann P, Shestakov SV, Borner T. 1995. Inactivation of a Synechocystis sp strain PCC 6803 gene with homology to conserved chloroplast open reading frame 184 increases the photosystem II-to-photosystem I ratio. Plant Cell 7: 649-658.

Wojciechowski MF, Lavin M, Sanderson MJ. 2004. A phylogeny of legumes (Leguminosae) based on analysis of the plastid matK gene resolves many well-supported subclades within the family. Am J Bot 91: 18461862 .

Wolfe KH, Li WH, Sharp PM. 1987. Rates of nucleotide substitution vary greatly among plant mitochondrial, chloroplast, and nuclear DNAs. Proc Natl Acad Sci 84: 9054-9058.

Wolfe KH, Sharp PM, Li W-H. 1989. Rates of synonymous substitution in plant nuclear genes. J Mol Evol 29: 208-211.

Wolfe KH, Morden CW, Palmer JD. 1992. Function and evolution of a minimal plastid genome from a nonphotosynthetic parasitic plant. Proc Natl Acad Sci 89: 10648-10652.

Wyman SK, Jansen RK, Boore JL. 2004. Automatic annotation of organellar genomes with DOGMA. Bioinformatics 20: 3252-3255.

Yang Z. 2007. PAML 4: Phylogenetic analysis by maximum likelihood. Mol Biol Evol 24: 1586-1591.

Yang Y, Sterling J, Storici F, Resnick MA, Gordenin DA. 2008. Hypermutability of damaged single-strand DNA formed at doublestrand breaks and uncapped telomeres in yeast Saccharomyces cerevisiae. PLoS Genet 4: e1000264. doi: 10.1371/journal.pgen.1000264.

Received June 20, 2010; accepted in revised form September 20, 2010.

\section{Genome Research


Genome Research 20: 1700-1710 (2010)

Localized hypermutation and associated gene losses in legume chloroplast genomes Alan M. Magee, Sue Aspinall, Danny W. Rice, Brian P. Cusack, Marie Sémon, Antoinette S. Perry, Saša Stefanović, Dan Milbourne, Susanne Barth, Jeffrey D. Palmer, John C. Gray, Tony A. Kavanagh, and Kenneth H. Wolfe

The structures of the two Trifolium repens cDNAs reported in Figure S6 of this paper are incorrect. The T. repens nuclear accD-coding region is fused to LPD1, not LPD2 as reported. We incorrectly assembled full-length cDNAs from expressed sequence tags, resulting in erroneous "recombination" between LPD1 and LPD2 in a region of high similarity about $200 \mathrm{bp}$ upstream of the $L P D 1-a c c D$ junction. Correct sequences of $L P D 1-a c c D$ and LPD2 cDNAs from both T. repens and T. pratense have been reported by Sabir et al. (2014) and deposited in GenBank (http://www.ncbi.nlm.nih.gov/genbank/) with accession numbers KF781540-KF781544. We have therefore withdrawn our $T$. repens cDNA sequences from the nucleotide databases (European Nucleotide Archive accession numbers HM029367-HM029368; http://www.ebi.ac.uk/ena/home).

The authors apologize for any inconvenience caused by this error and thank Jin Zhang, Bob Jansen, and Tracey Ruhlman for bringing it to our attention. This correction does not affect any of the paper's conclusions other than the name of the fusion gene.

Reference

Sabir J, Schwarz E, Ellison N, Zhang J, Baeshen NA, Mutwakil M, Jansen R, Ruhlman T. 2014. Evolutionary and biotechnology implications of plastid genome variation in the inverted repeat-lacking clade of legumes. Plant Biotech J doi: 10.1111/pbi.12179. 


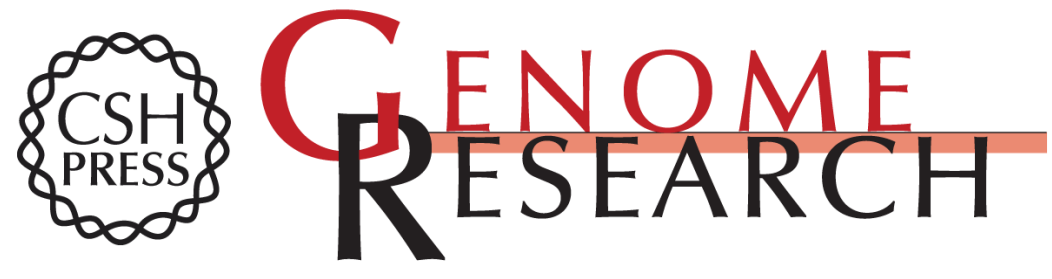

\section{Localized hypermutation and associated gene losses in legume chloroplast genomes}

Alan M. Magee, Sue Aspinall, Danny W. Rice, et al.

Genome Res. 2010 20: 1700-1710 originally published online October 26, 2010

Access the most recent version at doi:10.1101/gr.111955.110

\section{Supplemental http://genome.cshlp.org/content/suppl/2010/09/29/gr.111955.110.DC1 \\ Material}

Related Content Errata

Genome Res. June , 2014 24: 1052

References This article cites 90 articles, 23 of which can be accessed free at: http://genome.cshlp.org/content/20/12/1700.full.html\#ref-list-1

Articles cited in:

http://genome.cshlp.org/content/20/12/1700.full.html\#related-urls

\section{License}

Email Alerting Receive free email alerts when new articles cite this article - sign up in the box at the Service top right corner of the article or click here.

\section{Affordable, Accurate Sequencing.}

